\title{
ADULTS' PERSPECTIVE OF ENVIRONMENTAL ISSUES IN THE ISLAND OF RHODES
}

\author{
Dimitrios Poimenidis $^{1^{*}}$, Georgia loannidou $^{2}$, Sofia Poimenidou ${ }^{3}$ \\ ${ }^{1}$ Dr, University of the Aegean, Greece, poimenidis@aegean.gr \\ ${ }^{2} \mathrm{PhD}$ Candidate, University of the Aegean, Greece, gina.ioannidou@gmail.com \\ ${ }^{3} \mathrm{MSc}$ Department of Philosophy and Social Studies, University of Crete, \\ sophia poim@hotmail.com \\ ${ }^{*}$ Corresponding Author
}

\begin{abstract}
The general objective of advanced countries is sustainable development, as a current and future issue, while the indicators that mark the degree of success in this direction depend on a wide range of social, economic, and political processes and decisions. For these reasons, a field study was conducted concerning adultsin Rhodes'sarea duringNovember and December 2020. It was implemented with the use of a structured closedended questionnaire and sent to 460 adults by e-mail. The sample of the study consists of 159 participants, who sufficiently completed the data investigations. The questions were about demographicswith the selection of distinct answers, and Likert-scale answers. Using the statistical tool SPSS 23, data from the study were collected which are presented as percentage and on average answers. The findings suggest to a great extent the human impact onthe current social and environmental issues. Concurrently, the high degree of their significance in the modern world and their negative impactin the ecosphere are accurately indicated in the study; issues that arehighlighted in the international bibliography. At the same time, the study shows that the participants have an extensive knowledge of the current issues, and it highlights the Mass Media's crucial role as source of information in encouraging knowledge about environmental concerns. Financial incentives, the implementation of training courses for adults, the essential requirements to ensure products meet high health, safety and environmental standards are additional measures taken to lessen the human impact on the physical environment. Taking individual responsibility, limiting the production, consumption and waste management are key elements in redefining the citizens' environmentally responsible behavior and work towards strengthening the conditions for the implementation of key processes for sustainable development.
\end{abstract}

Keywords: Environmental issues, knowledge, opinions, adults

\section{INTRODUCTION}

Social reality is based on the exploitation of natural ecosystems and resources to meet the needs (Bansard \& Schröder, 2021) and the growth of the world's urban population (OECD / EU 2020; Ritchie \& Roser, 2018). This means an increase in demand for food, water, housing, electricity, roads, cars, and many products or needs. Abiotic and biotic factors that work together to create unique ecosystems are treated as resources that meet the needs of the modern citizen (Summers et all., 2012).

Humans affect the earth's ecosystem in many ways as the exploitation of natural resources is significantly related to environmental problems worldwide. The effects of the human impact on the natural environment are related to the social issues local communities face, which humans refer to as environmental issues, renouncing their responsibility or indirectly taking responsibility on account of development (Castro Pereira, 2015). Apart from that, the relationship between humans and the environment is symbiotic, yet onesided. As populations grow around the world and as large industrialized or industrializing countries continue 
to exploit the planet's natural resources, the relationship between people and the environment changes, and mostly for the worse (Arora, 2019). The region, the area, and the political, social, and historical factors are distinctive features ofthe environmental degradation as they are not only directly or indirectly related to their generative cause, the emergence and intensity but also to the possibility of eliminating or reducing them.

The major issue concerning human intervention on the environment is the exploitation of natural resources for economic growth since they are important for any country (OECD, 2011). The development of modern societies is understood mainly according to their economy, as product manufacturing, the consumption of goods and their disposal are related to a person's well-being and happiness and the economic benefit that results from the life cycle of a product (UNEP, 2015). Environmental degradation in terms of economic growth refers to a broad process through which environmental health and biodiversity are under threat (Shrinkhal, 2019; Bierbaum et al. 2018). This process can be natural, or it can be caused and accelerated by human activities (Shrinkhal, 2019).

Many international organizations recognize that environmental deterioration is one of the major threats to Earth. If the environment is irreparably affected, this could mean the beginning of further destructive effects (Smith, 2013). However, the natural environment is the most valuable "asset" we have as the air, water, soil, minerals, plants, and animals are the Earth's natural resources and are essential for the society and the economy as they provide fundamental life support and should not be taken for granted (OGL, 2018).

Humans impact the physical environment in many ways such as pollution, global warming, ozone depletion, acid rain, resources depletion, overpopulation, waste generation, deforestation, burning fossil fuels and biodiversity loss (Oswald Spring, 2016; Jianping, 2014; Camill, 2010), leading to environmental problems as humanity's rapidly growing consumption of natural resources is causing severe damage. Nevertheless, people's understanding of the catastrophic environmental consequences could potentially enhancetheir environmental concern and effort to act in environmentally friendly ways, resulting to a greater sense of environmental responsibility (Janmaimool \& Chudech, 2020).

Environmental problems are defined as the harmful effects of human activities and behavior on the terrestrial environment (McMichael et al., 2008). More specifically, serious environmental questions have been raised over the last decades regarding environment and its conservation (Dunlap \& Jorgenson, 2012). However, the paradox of this situation is that, while the degradation of the environment and the cause of the corresponding problems are regional, their effect is at a global level. Yet, natural resources were created for the enjoyment of humankind and not for the enjoyment of any particular person. They are the key factors for human development and human conditions. Thus, the human impact on the environment goes beyond the narrow local boundaries as these natural elements do not belong to anyone but to all (ccsu.edu, n.d.). Finally, globalization and internationalization necessitate a globalized approach and solution of these issues (Kaypak, 2012).

\section{ENVIRONMENTAL CITIZENSHIP}

The collaboration of governments, the corporate world and citizens is necessary to resolve environmental issues (van Noordwijk et al., 2021). However, regarding citizens, the expected results of their behaviors are not always feasible and, thus, a discrepancy arises between the final outcome and what the citizen is expected to do. This stems from the fact that environmental impacts depend on a combination of social, ecological, and economic practices (Shirk et al., 2012), especially when changes have been made in resource management and practices that affect the natural environment. Institutional and collective practices as well as individual behavior are in a constant interactive sequence and any changes can lead to different practices.

Environmental knowledge is considered the key element in environmental education (Otto \& Pensini, 2017; Otto et al., 2016), which is a prerequisite for promoting sustainable consumption and environmentally friendly behavior in the wider context of environmental education and sustainability (Michelsen \& Fischer, 2017). Being environmentally friendly means having a lifestyle that is better for the environment. Thus, individuals need to develop a deeper understanding of environmental issues and have the skills to make informed and responsible decision. Thus, environmental education is the key pillar in addressing ecological issues for sustainable development (Van Poeck, 2014).

In addition, social learning becomes a relevant interpretive framework for the assessment and management of natural resources. This means constant redefinition of the usual roles that scientists, policymakers and citizens play regarding sustainability (Jacobi, et al., 2016). As a result, people need to change the way they think and act by acquiring and shaping knowledge, skills, values and attitudes, elements that offer the opportunity to contribute to sustainable development (UNESCO, 2017). 


\section{METHODOLOGY}

Modern human society has a negative impact on the environmentworld-wideleading to global warming, biodiversity loss, pollution, which has a negative effect on the ecosystems and human health, sea level rise, extreme climate events, diseases, food safety and so on (Camill, 2010).

The aim of the present study is to explore the views of adult citizens regarding current social and environmental issues, their importance, accountability for the probable cause, how informed the participants are and their source of information. In addition, the study examines the growing pressures on the ecosphere, to what degree actions are important to reduce the ecological footprint, to what extent the proposed solutions are important to reduce or eliminate the problems and to what extent the suggested educational proposals are important toreduce or eliminate the problems in the context of education for sustainable development. Suffice to say, the participants' perceptions on the environmental conditions are essential as they verify their attitude towards the environmental problems which is necessary to redefine their overall behavior (Nash et al., 2019).

The research was conducted with an anonymous closed-ended questionnaire (Google forms), which was sent by e-mail to the participants, as it was considered the most appropriate approach for the implementation of this research (Taherdoost, 2016). 460 questionnaires were sent to adults in the town of Rhodes during December 2020, of which 159 were sufficiently completed and they comprise the study's samples. The questionnaire included nominal questions and five-point Likert scale questions (1: least important - 5: very important). The data was coded and processed with the statistical software SPSS 23 and are presented, depending on the type of variables. They are reported descriptively presenting percentages in the participants' statements and with Averages. Issues were kept to regarding the participants' anonymity as well as the research's objectivity and validity during the process.

According to the study's demographic data, $69.2 \%$ of the participants were women, $32.2 \%$ were men and one statement was genderless. $35.7 \%$ of the study subjects were the parents of school students $(35.7 \%)$ and $36.3 \%$ were teachers while some participants were students $(15.7 \%)$ where as $12.1 \%$ did not declare their status. Regarding the participants' age, $14.5 \%$ were from 18 to 30 years old, $29.6 \%$ were from 31 to 40 , $32.1 \%$ were from 41 to 50 , and $23.9 \%$ were 51 to 60 . Regarding the participants' educational status, $54.1 \%$ had university education, $34 \%$ were postgraduate degree or doctorate holders while the rest of the participants had compulsory basic education (19.4\%).

\section{STUDY FINDINGS}

As far as the most crucial contemporary issues are concerned, the participants indicate that they identify as social issues, racism (84.3\%), immigration $(58.5 \%)$, terrorism $(74.2 \%)$, education $(63.5 \%)$, human rights $(73.6 \%)$ and poverty $(71.7 \%)$. Respectively, as social but mainly environmental issues are identified deforestation $(67.9 \%)$, acid rain $(69.8 \%)$, stratospheric ozone depletion $(64.2 \%)$, greenhouse effect $(61 \%)$, water pollution $(51.6 \%)$, biodiversity reduction $(52.2 \%)$, soil erosion / leaching $(61 \%)$ and air pollution (53.5\%). Finally, as social and environmental issues concurrently are recognized war (69.8\%), urbanization $(64.2 \%)$, overpopulation $(71.1 \%)$, diseases and infectious viruses $(58.5 \%)$, the use of nuclear materials $(63.5 \%)$, energy production and use (57.9\%), traffic congestion $(64.2 \%)$ and stray animals $(54.1 \%)$. Waste is classified not only as an environmental issue (48.4\%) but also as a social one $(49.1 \%)$.

Regarding the significance of the issues referred to with an average rating on a 5-point scale, very high importance is attached to war (4.80), education (4.74), human rights (4.72), the use of nuclear materials (4.65), water pollution (4.60), poverty (4.59), air pollution (4.53), social inequality and discrimination (4.53), waste generation and management (4.53), the existence of diseases and viruses $(4,52)$, terrorism $(4,51)$ and in the greenhouse effect $(4,50)$.

Great importance is attached to ozone depletion $(4,50)$, deforestation $(4,45)$, biodiversity reduction $(4,39)$, migration $(4,38)$, energy production and use $(4,38)$, racism $(4.33)$, acid rain $(4.20)$, soil erosion and leaching (4.17) and overpopulation (4.03).

Issues regarding traffic congestion (4.00), urbanization (3.87) and stray animals (3.87) are considered quite important.

Apportioning responsibility for the above-mentioned questions (on a 5-point Likert scale), the participants state the citizens are mainly responsible for ensuring a healthy environment $(73.6 \%)$. They are concerned as technology alone cannot solve all environmental problems (86.8\%). They elaborate human beings should not consume natural resources uncontrollably as full recovery of the ecosystem can take years, decades or even 
hundreds of years $(90.5 \%)$ and that it is essential to reduce energy consumption in their daily life $(69.8 \%)$. They also establish that people need to worry about waste and recycling $(62.3 \%)$, and that human activity is causing environmental degradation (84.8\%) while nature does not have sufficient mechanisms to reduce or even eliminate the human impact $(93.7 \%)$. The study subjectsare interested in participating in activities concerning environmental protection (57.8\%). In contrast, they do have the intention to buy fewer products (just the essentials) to reduce their ecological footprint (42.6\%). In addition, they do not apportion responsibility to society as a whole butthey accept the individual responsibility $(82.2 \%)$, while they intend to save energy to a satisfactory extent (to some extent $45.5 \%$ and rather much / very much $26.4 \%$ ).

Regarding the participants' views on environmental issues in general, they state that they are not problems asnaturally occurring processes alter the Earth $(70.4 \%)$ but they are the anthropogenic processes produced by Man's activities that impact the physical environment $(82.3 \%)$, while in the statement that the natural hazards are elements of the physical environment that are aggravated by the Man's interventions in the ecosystem, the study subjects' answers do not deviate significantly. Moreover, the participants state that the environmental issues do concern them to a significant degree (57\%).

Participants obtain information about environmental issues to a small extent during their studies at a higher education institution (more or less, 52.2\%), from Postgraduate programs (more or less, $75.5 \%$ ), scientific conferences and various related presentationsat workshops (more or less, 58.5\%), from Non-governmental or Environmental organizations (more or less, 58.\%) and statutory authority such as the European Union, the Center for Renewable Energy Sources (CRES), the Ministry of Energy and Environment, EPA USA and so on (little, 63.7\%).

They get more information from television and the media (to some extent $34.6 \%$, rather much / very much $34.6 \%$ ), the internet (to some extent $25.2 \%$, rather much / very much $67.9 \%$ ), magazines (to some extent $32.3 \%$, rather much / very much $30.4 \%$ ) and friends and acquaintances who are interested in or have knowledge of the environmental issues (to some extent $27 \%$, rather much / very much $32.1 \%$ ). Regarding information obtained about the physical environment while attending short-term training programs, the statements are evenly distributed (little $50.3 \%$, to some extent $20.8 \%$, rather much / very much $28.9 \%$ ).

The participants acknowledge that the issues which have the greatest impact on the environment in terms of the personal and family life concern food overconsumption (to some extent $35.2 \%$, rather much / very much $54.7 \%$ ), bottled water use (to some extent $30.8 \%$, rather much / very much $41.5 \%$ ), product packaging purchased in the household sector (to some extent $27 \%$, rather much / very much $66.7 \%$ ), electricity consumption (to some extent $19.5 \%$, rather much / very much $74.2 \%$ ), extensive use of electrical appliances (to some extent $24.5 \%$, rather much / very much $67.9 \%$ ), extensive use of cars in daily life (to some extent $15.1 \%$, rather much / very much $78.7 \%$ ), non-use of bicycles, where they can be used (to some extent $18.9 \%$, rather much / very much $71.1 \%$ ) and the improper waste management by the municipalities that are responsible for waste treatment (to some extent $13.2 \%$, rather much / very much $83 \%$ ). Respectively, the participants' answers are evenly distributed regarding the use of public transport and the use of water in the gardens as the study subjects do not consider these issues have the greatest impact on the environment.

In addition, regarding the question about the "several environmental issues that would have been significantly reduced or eliminated", the participants state that the non-use of food and energy products (to some extent $30.8 \%$, rather much / very much $48.4 \%$ ), the significant restriction of materials'use and energy (to some extent $26.4 \%$, rather much / very much $64.7 \%$ ), the restriction of materials' use, packaging and so on (to some extent $33.3 \%$, rather / very much $35.2 \%$ ) and the restriction of energy use (to some extent $34.6 \%$, rather much / very much $30.9 \%$ ) would have a very positive effect on the reduction of the current environmental problems, acknowledging the need to change the modern consumer and energy-intensive life style. Moreover, concerning the statement "if we did not make any change in our daily life but only intensified the waste recycling processes", there is a significant refusal rate (not at all / little 69.8\%), indicating that recycling alone cannot bring significant positive results, when the other sectors do not comply with the logic of reduction.

Regardingthe measures to address environmental issues at the economic and state level, the participants identify that the state must establish stricter environmental criteria in the construction and industry sector and impose them to citizens (to some extent $11.3 \%$, rather much / very much $87.4 \%$ ). Financial incentives should be given to individuals to purchase eco-friendly energy appliances (to some extent $14.5 \%$, rather much / very much $81.8 \%$ ). The production of materials such as disposable plastics that significantly burden the environment and intensify the energy issue should be prohibited (to some extent $7.5 \%$, rather much / verymuch $90 \%$ ). Industrial units should be compelled to recycle electrical appliances or products (to some extent $10.1 \%$, rather much / very much $87.4 \%$ ), the manufacture of disposable plastic materials should be 
banned (to some extent $10.1 \%$, rather much / very much $87.4 \%$ ) and heavy fines should be imposed in cases where the construction specifications and the recycling procedures are not abided by (to some extent $13.2 \%$, rather much / very much $86.8 \%$ ). It is noteworthy that all the statements of possible counter measures take high percentages of positive positions.

Regarding the measures to address environmental issues at education level, it is vital that adult education should be promoted with the design of specific programs of targeted educational interventions by the state (to some extent $17 \%$, rather much / very much $79.8 \%$ ) and bythe local municipalities (to some extent $14.5 \%$, rather much / very much $81.1 \%$ ), with the design and promotion of educational television for the public (to some extent $15.1 \%$, rather much/ very much $81.1 \%$ ), with the design of a single database with relevant material such as saving guide, rational energy and material use or non-use (to some extent $14.5 \%$, rather much / very much $80.5 \%$ ) and the establishment of more environmental programs by universities with open access forthe public (to some extent $14.5 \%$, rather much / very much $82.4 \%$ ).

\section{DISCUSSION AND CONCLUSSIONS}

Understanding the dimensions of the ecosphere destruction is crucial as the environmentally informed and critically thinking citizen can significantly diminish the environmental degradation for which man himself is responsible, usually unconsciously. As the anthropogenic problems of the environment are ahead of us and it is up to us whether there is deterioration or improvement, the study participants, who have a high level of education in general, recognize precisely and classify correctly the current social and environmental issues highlighting their anthropogenic dimension (Shrinkhal, 2019; CEB 2015).

Simultaneously, the degree of importance is also accepted regarding the most crucial among them (war, racism, human rights and social discrimination, etc) both on a social level and that of deterioration of the biosphere. These issues include depletion of the ozone layer, deforestation, biodiversity decline, air and water pollution, acid rain, overpopulation, etc. (European Commission, 2021). Their importance likely reflects the average person's concern as a first step towards a more environmentally friendly behaviour on a metalevel. At the same time, the personal responsibility of the individual, on a daily behaviour and decisions level, is also recognized, rightly considering that technology, which in recent years has proven a powerful weapon against environmental degradation, cannot prevent and correct the environmental impact of reckless human behaviour, but apparently only partially scale down the issue.

Hence the need is emerging for containment of overconsumption of materials, products and energy to the level of their daily lives (Meenakshi, 2021). That these are social problems is also emerging as knowledge as they concern the choices of the contemporary human on a daily personal and social level and in the living standards, he himself has shaped. In particular, reduction of energy consumption, plastic and bottled water, packaging materials, the plethora of possessions and use of gadgets and appliances, consumption of electricity and the widespread use of cars as opposed to bicycle use and the production and management of waste constitute the most significant of impact parameters.

Television, the Media, the Internet and various magazines appear to be contributing substantially towards enhancing their environment-friendly behaviour, while the potential of modern media and information is also making its presence felt (Ors, 2012). It also seems that their studies or Master's degrees, though most are of a university education, have not provided a satisfactory gnostic base on environmental issues, and neither have the potential actions of NGOs and other official legally established bodies (EU, Green electricity, Ministry of Energy and Environment, etc.).

Among possible supporting measures for the reduction of environmental impact there are those suggested for the adoption of educational programs for the general public, as education is a contributing factor to the development and alteration of human behaviour within the guidelines for sustainable development. On a par, it is proposed the media, as a powerful factor in shaping perceptions and views is exploited (Ors, 2012; Seema, 2012) while the creation of an open access database for the general public, would be another important asset in informing people. Of course, the potential of higher education, where university information programs open to the general public could be established, is not excluded.

However, the use of more restrictive measures, though many developed countries have adopted stricter environmental regulations ( $\mathrm{Xu}$ et al., 2013), could bring significant environmental benefits including the introduction of stricter criteria on environmental guidelines and incentives for the general public to buy energy-saving appliances. Furthermore, the issue of restricting the manufacture and use of plastics and the obligation for manufacturing industries to phase out materials themselves are equally important compensatory measures helping the environment. 
In general, accepting personal responsibility, reducing production, availability, consumption and disposal of materials could provide the conditions for a healthier environment and make a significant positive contribution to sustainable development. Adults, also, express positive opinions on the environment by forming their own view regarding the human origin of environmental issues, recognising man's contribution to their creation and deterioration. It should not be overseen that the environment is the fundamental basis for human and other life support and the guarantee of sustainable human development (Jianping et. al., 2013).

\section{REFERENCE LIST}

Arora, N. (2019). Earth: 50 years challenge. Environmental Sustainability, 2, 1-3. https://doi.org/10.1007/s42398-019-00053-5

Bansard, J. \& Schröder, M. (2021). The Sustainable Use of Natural Resources: The Governance Challenge. BRIEF \#16, International Institute for Sustainable Development. Accessed 20.07.2020 from: https://www.iisd.org/system/files/2021-04/still-one-earth-natural-resources.pdf

Bierbaum, R., Cowie, A., Barra, R., Ratner, B., Sims, R., Stocking, M., Durón, G., Leonard, S. \& Whaley, C. (2018). Integration: to solve complex environmental problems. Scientific and Technical Advisory Panel to the Global Environment Facility. Washington, DC. 10.13140/RG.2.2.34698.52162

Camill, P. (2010). Global Change. Nature Education Knowledge, 3(10), 49.

Castro Pereira, J. (2015). Environmental issues and international relations, a new global (dis)order - the role of International Relations in promoting a concerted international system. Revista Brasileira de Política Internacional, 58 (1): 191-209.

ccsu.edu. (n.d.). International environmental problems and global search for solutions. Retrieved from: https://web.ccsu.edu/faculty/kyem/GEOG433/International Problems/INTERNATIONAL ENVIRONME NTAL PROBLEMS.htm [Online Resource]

CEB. (2015). Addressing Environmental Challenges and their Social Implications in Europe. Retrieved from https://coebank.org/media/documents/ECS Study Environmental challenges FINAL low resolution. pdf [Online Resource]

Dunlap, R. E. \& Jorgenson, A. K. (2012). Environmental Problems. In (Ed.) G. Ritzer, The Wiley-Blackwell Encyclopedia of Globalization. https://doi.org/10.1002/9780470670590.wbeog174

European Commission. (2021). Pathway to a Healthy Planet for All EU Action Plan: 'Towards Zero Pollution for Air, Water and Soil', Brussels, COM 400 final. Retrieved from:

https://ec.europa.eu/environment/pdf/zero-pollution-action-plan/communication en.pdf

Jacobi, P. R., de Toledo, R. F. \& Grandisoli, E. (2016). Education, sustainability and social learning. Brazilian Journal of Science and Technology, 3(3). https://doi.org/10.1186/s40552-016-0019-2

Janmaimool, P \& Chudech, S. (2020). Effect of Domestic and Global Environmental Events on Environmental Concern and Environmental Responsibility among University Students. Sustainability, 12(4), 1-20.

Jianping L., Minrong L., Jinnan W., Jianjian L., Hongwen S. \& Maoxing H. (2014). Global Environmental Issues and Human Wellbeing. In: Jianping L., Minrong L., Jinnan W., Jianjian L., Hongwen S., Maoxing H. (eds) Report on Global Environmental Competitiveness. Current Chinese Economic Report Series. Springer, Berlin, Heidelberg. https://doi.org/10.1007/978-3-642-54678-5 1

Kaypak, Ş. (2012). Sustainability and Ecopolitics in the Solution of Global Environmental Problems. 2nd International Congress on Urban and Environmental Issues and Policies, 04-06 May 2012, Papers and Proceedıngs of Congress, p.375-392.

McMichael, A. J., Friel, S., Nyong, A. \& Corvalan, C. (2008). Global environmental change and health: impacts, inequalities, and the health sector. BMJ (Clinical research ed.), 336(7637), 191-194. https://doi.org/10.1136/bmj.39392.473727.AD

Meenakshi, K. S. (2021). Environmental Pollution: Causes and Prevention. Quest Journals, Journal of Research in Environmental and Earth Science, 7(6), 80-85. 
Michelsen, G. \& Fischer, D. (2017). Sustainability and education. In (Eds) M.V. Hauff \& C. Kuhnke, Sustainable Development Policy: A European Perspective. Routledge: London, UK.

Nash, N., Capstick, S., Whitmarsh, L., Chaudhary, I. \& Manandhar, R. (2019). Perceptions of Local Environmental Issues and the Relevance of Climate Change in Nepal's Terai: Perspectives From Two Communities. Frontiers in Sociology, 4, 60. https://doi.org/10.3389/fsoc.2019.00060

Nwankwoala, H. N. L. (2015). Causes of Climate and Environmental Changes: The need for EnvironmentalFriendly Education Policy in Nigeria. Journal of Education and Practice, 6(30), 224-234. ISSN 22221735

OECD. (2011). The Economic Significance of Natural Resources: Key points for reformers in Eastern Europe, Caucasus and Central Asia. Paris: OECD.

OECD/EU. (2020). Cities in the World: A new perspective on urbanization. Accessed 20.07 .2020 from: https://www.oecd.org/regional/regional-statistics/

OGL. (2018). Our Waste, our Resources: A Strategy for England. Online available at: https://www.gov.uk/government/publications/resources-and-waste-strategy-for-england\#history

Ors, F. (2012). Environmental education and the role of media in environmental education in Turkey. Procedia - Social and Behavioral Sciences, 46, 1339 - 1342.

Oswald Spring, Ú. (2016). Perspectives of Global Environmental Change in the Anthropocene. EInternational Relations, ISSN 2053-8626.

Otto, S. \& Pensini, P. (2017). Nature-based environmental education of children: Environmental knowledge and connectedness to nature, together, are related to ecological behavior. Global Environmental Change,. 47, 88-94.

Otto, S.; Neaman, A.; Richards, B. \& Marió, A. (2016). Explaining the ambiguous relations between income, environmental knowledge, and environmentally significant behavior. Society \& Natural Resources, 29(5), 628-632. DOI: 10.1080/08941920.2015.1037410

Ritchie, H. \& Roser, M. (2018). "Urbanization". Published online at OurWorldlnData.org. Retrieved from: https://ourworldindata.org/urbanization [Online Resource]

Seema, S. (2012). Environmental concerns and role of media in environment management: a few possibilities. Management Dynamics, 12(2), 71-80.

Shirk, J. L., Ballard, H. L., Wilderman, C. C., Phillips, T., Wiggins, A., Jordan, R., McCallie, E., Minarchek, M., Lewenstein, B. V., Krasny, M. E. \&. Bonney, R. (2012). Public participation in scientific research: A framework for deliberate design. Ecology and Society, 17(2), 29. https://doi.org/10.5751/ES-04705170229.

Shrinkhal, R. (2019). Economics, Technology, and Environmental Protection: A Critical Analysis of Phytomanagement. In (eds) V. C. Pandey \& K Bauddh, Phytomanagement of Polluted Sites, Chapter 22. p. 569-580, Elsevier. ISBN 9780128139127

Smith, S. E (2013). Environmental Degradation. Article from wiseGEEK. Online available at: www.wisegeek.com/what-is-environmental-degradation.htm

Summers, J. K., Smith , L. M., Case , J. L. \& Linthurst, R. A. (2012). A Review of the Elements of Human Well-Being with an Emphasis on the Contribution of Ecosystem Services. Ambio, 41(4): 327-340. https://doi.org/10.1007/s13280-012-0256-7

Taherdoost. H. (2016). How to Design and Create an Effective Survey/Questionnaire; A Step by Step Guide. International Journal of Academic Research in Management, 5(4), 37-41, ISSN: 2296-1747

UNEP. (2015). Sustainable Consumption and Production. A Handbook for Policymakers. United Nations Environment Programme, Nairobi, Kenya. ISBN: 978-92-807-3364-8

UNESCO. (2017). Education for Sustainable Development Goals. Learning Objectives. ISBN 978-92-3100209-0. Retrieved from: https://www.unesco.de/sites/default/files/201808/unesco education for sustainable development goals.pdf

van Noordwijk T., Bishop, I., Staunton-Lamb, S., Oldfield, A., Loiselle, S., Geoghegan, H., \& Ceccaroni, L. (2021). Creating Positive Environmental Impact Through Citizen Science. In: Vohland K. et al. (eds) 
The Science of Citizen Science. Springer, Cham. https://doi.org/10.1007/978-3-030-58278-4 19

Van Poeck, K. (2015). Education as a response to sustainability issues. Practices of environmental education in the context of the UN Decade of Education for Sustainable Development. Environmental Education Research. 21(4), 649. https://doi.org/10.1080/13504622.2014.958651

Xu, L., Mathiyazhagan, K., Govindan K., Haq, A. N., Ramachandran, N V. \& Ashokkumard, A. (2013). Multiple comparative studies of Green Supply Chain Management: Pressures. Resources, Conservation and Recycling, 78, 26-35. https://doi.org/10.1016/..resconrec.2013.05.005 